\title{
Bilateral pulmonary embolism without deep venous thrombosis was observed after knee arthroscopy: a case report
}

Yuan Li ${ }^{1+}$, You-Xia Chen ${ }^{2 \dagger}$, Xiang-Tian Deng ${ }^{1,3}$, Shun-cheng Yang ${ }^{1}$, Zhi-Yuan Su', Yu-Nong Ao ${ }^{1}$, Peng Zhou', Fu-Yuan Deng ${ }^{1}$, Zhong Li ${ }^{1 *}$ and Jun-Cai Liu' ${ }^{1 *}$

\begin{abstract}
Background: Symptomatic pulmonary embolism (PE) after knee arthroscopy is extremely rare. If the embolism is not treated promptly, the patient may die. Bilateral pulmonary embolism with associated pulmonary infarct without concomitant deep vein thrombosis has never been reported following routine knee arthroscopy.

Case presentation: A 50-year-old female patient with no other risk factors other than hypertension, obesity, varicose veins in the ipsilateral lower extremities and elevated triglyceride (TG) presented to our ward. She had experienced sudden chest tightness, polypnea and fainting after going to the bathroom the morning of the second postoperative day and received emergency medical attention. Colour ultrasonography of the extremities showed no deep vein thrombosis. Lung computed tomography angiography (CTA) showed multiple embolisms scattered in both pulmonary artery branches. Thus, emergency interventional thrombolysis therapy was performed, followed by postoperative symptomatic treatment with drugs with thrombolytic, anticoagulant and protective activities. One week later, lung CTA showed a significant improvement in the PEs compared with those in the previous examination. Since the aetiology of PE and no obvious symptoms were discerned, the patient was discharged.

Conclusion: Although knee arthroscopy is a minimally invasive and quick procedure, the risk factors for PE in the perioperative period should be considered and fully evaluated to enhance PE detection. Moreover, a timely diagnosis and effective treatment are important measures to prevent and cure PE after knee arthroscopy. Finally, clear guidelines regarding VTE thromboprophylaxis following knee arthroscopy in patients with a low risk of VTE development are needed.
\end{abstract}

Keywords: Pulmonary embolism, Knee arthroscopy, Thrombus prevention, Pulmonary embolism treatment

\section{Background}

Pulmonary embolism (PE) is one of the major causes of sudden death during orthopaedic perioperative care, with a mortality rate that is second only to cancer and myocardial infarction [1]. PE is common in lower limb

\footnotetext{
* Correspondence: 545890312@qq.com; 1220223982@qq.com

'Yuan Li and You-Xia Chen contributed equally to this work.

'Department of Orthopaedics, the Affiliated Hospital of Southwest Medical

University, Sichuan Provincial Laboratory of Orthopaedic Engineering,

Luzhou, Sichuan 646000, People's Republic of China

Full list of author information is available at the end of the article
}

surgery patients. Without thromboprophylaxis, the incidence of thrombotic events in total hip and knee replacement patients ranged from 29 to $60 \%[2,3]$, and that of PE in knee arthroscopy patients was $4 \%$ [4]. There is a lack of data on the incidence of VTE in patients undergoing knee arthroscopy. Acute PE after conventional knee arthroscopy is extremely rare. Here, we report a case of successful treatment of acute PE without deep vein thrombosis (DVT) after debridement.

C C The Author(s). 2021 Open Access This article is licensed under a Creative Commons Attribution 4.0 International License, which permits use, sharing, adaptation, distribution and reproduction in any medium or format, as long as you give appropriate credit to the original author(s) and the source, provide a link to the Creative Commons licence, and indicate if changes were made. The images or other third party material in this article are included in the article's Creative Commons licence, unless indicated otherwise in a credit line to the material. If material is not included in the article's Creative Commons licence and your intended use is not permitted by statutory regulation or exceeds the permitted use, you will need to obtain permission directly from the copyright holder. To view a copy of this licence, visit http://creativecommons.org/licenses/by/4.0/ The Creative Commons Public Domain Dedication waiver (http://creativecommons.org/publicdomain/zero/1.0/) applies to the data made available in this article, unless otherwise stated in a credit line to the data. 


\section{Case presentation}

A 50-year-old female patient with an eight-plus-year history of hypertension $(140-180 / 80-103 \mathrm{mmHg}$ ) and body mass index (BMI) of $36.3 \mathrm{~kg} / \mathrm{m}^{2}$ was admitted to our ward due to pain during right knee joint movement for more than a year and aggravation for more than 4 months. The patient had no malignancy or venous thromboembolism (VTE) history; she had ipsilateral varicose veins and no use of anticoagulants or hormones. Magnetic resonance imaging (MRI) confirmed a degree II-III injury of the posterior horn of the medial meniscus of the right knee. On May 17, 2019, knee arthroscopy in the right knee cavity was performed under lumbar anaesthesia. The patient was operated on in a suspended-leg position. The tourniquet pressure was $260 \mathrm{mmHg}$, the perfusion pressure in the joint cavity was $70 \mathrm{mmHg}$, the tourniquet time was $25 \mathrm{~min}$, and the bleeding volume was approximately $5 \mathrm{~mL}$. She received postoperative fluid replenishment and pain relief and underwent physical therapy involving straight leg-raises and ankle pumping exercises. The patient did not receive any pharmacologic thromboembolic prophylaxis. She left the bed and walked on the first postoperative day, and she experienced sudden chest tightness, polypnea and fainting after going to the bathroom the morning of the second postoperative day. She received emergency medical care, including electrocardiogram (ECG) monitoring (peripheral oxygen saturation $\left(\mathrm{SpO}_{2}\right)$ : 92\%, P: 98 times/min, R: 20 times/min, Bp: 103/51 $\mathrm{mmHg}$ ). Lung auscultation revealed moist rales in both lungs. No abnormalities were detected in the blood examination ( $\mathrm{N}$-terminal-pro-hormone brain natriuretic peptide (NT-pro BNP): $896.40 \mathrm{ng} / \mathrm{L}$, oxygen saturation of arterial blood (SaO2):85\%, partial pressure of carbon dioxide (PCO2): $36 \mathrm{mmHg}$, D fragments of fibrin protein (D-dimer): $14.77 \mu \mathrm{g} / \mathrm{mL}, \mathrm{pH}: 7.452$, fibrin degradation product (FDP): $54.97 \mu \mathrm{g} / \mathrm{ml}$, creatine kinase myocardial band (CK-MB): $7.4 \mu \mathrm{g} / \mathrm{L}$, and high-sensitivity troponin $\mathrm{T}$ (hs -TnT): $0.16 \mu \mathrm{g} / \mathrm{L}$ ). Doppler ultrasounds of the extremities showed normal blood flow, with no evidence of
DVT or obstruction. Computed tomography (CT) angiography showed multiple scattered embolisms in both pulmonary artery branches (Fig. 1). After emergency interventional thrombolytic therapy, the emboli in the pulmonary trunk and branches was significantly improved (Fig. 2), and the symptoms of chest tightness and respiratory distress were significantly relieved, with an $\mathrm{SpO} 2$ of $96 \%$ and a BP of 112/75 mmHg. Postoperative medication (5 days) consisted of low-molecular weight heparin $0.6 \mathrm{~mL}$ ih q $12 \mathrm{~h}, 400,000$ units of urokinase, and $0.9 \%$ NS $100 \mathrm{~mL}$ iv gtt q $12 \mathrm{~h}$. After $2 \mathrm{~h}$ of immobilization of both lower limbs, the patient received physical therapy including knee range of motion, ankle pump and strength exercises targeting the anterior and posterior muscle groups. Pulmonary CTA was performed again on the 6th day after drug thrombolysis therapy and indicated that the pulmonary thrombi in both lungs were significantly reduced compared to those in the previous examination, with partial revascularization and clear pulmonary vascular lines (Fig. 3). The patient was discharged after evidence of improvement and received rivaroxaban $20 \mathrm{mg}$ qd orally for 3 months, with monthly follow-up outpatient visits.

\section{Discussion}

There are clear guidelines for preventing thrombus formation in the perioperative period of major orthopaedic surgery, but there is no consensus on this approach after arthroscopic surgery. Abram et al. [5] reported that the incidence of symptomatic venous thromboembolism (VTE) within 9 months after arthroscopic partial meniscal resection was approximately $0.078 \%$. Lau et al. [6] reported that the incidence of VTE after knee arthroscopy in children was $0.27 \%$. Some physicians believe that conventional knee arthroscopy is simple and quick, and serious complications are rare. Indeed, the risk of thrombosis is low, so there is no need for thrombosis prevention in the perioperative period [7-10]. Recently, some cases of symptomatic DVT and PTE after partial meniscus resection, anterior cruciate ligament
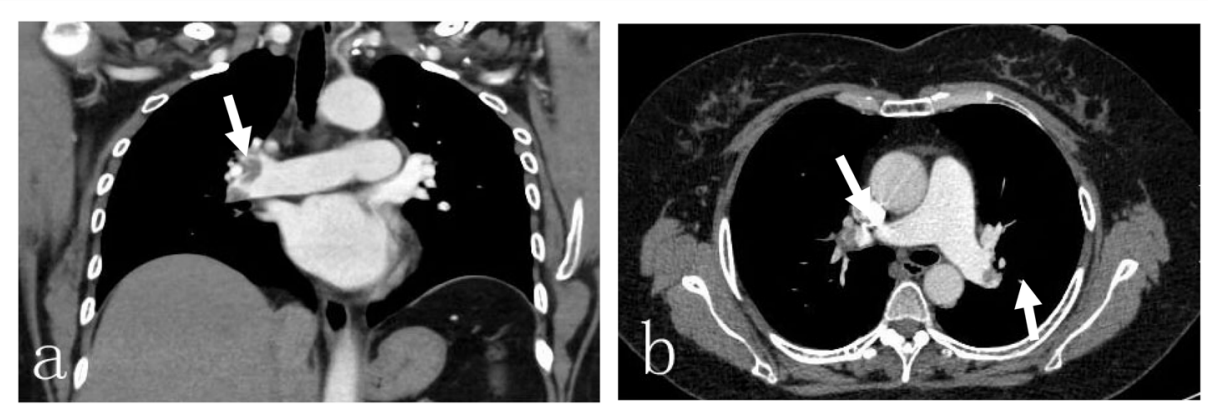

Fig. 1 Pulmonary CTA showing multiple scattered emboli in both pulmonary artery branches, a coronal view showing a massive PE in the right main pulmonary artery (white arrow), b axial view showing a massive PEs in the left and right main pulmonary arteries (white arrow) 

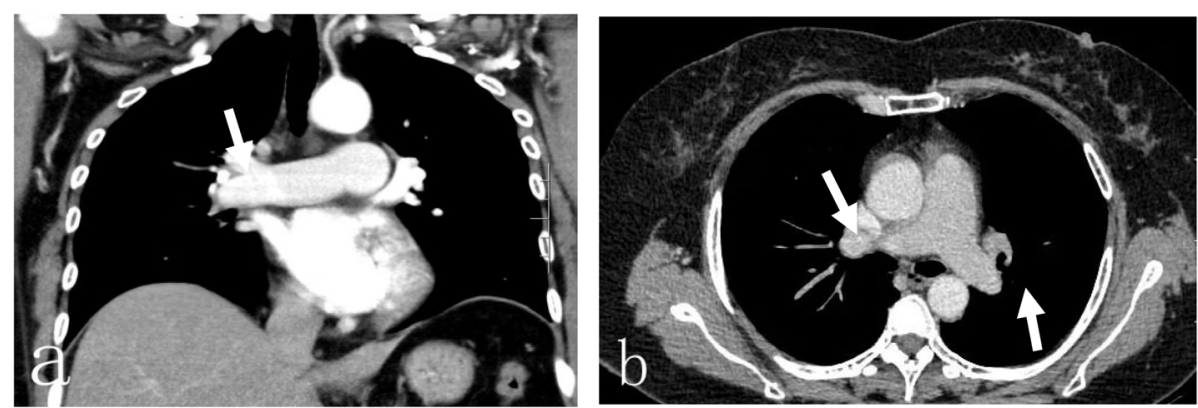

Fig. 2 After emergency interventional thrombolytic therapy, the emboli in the pulmonary trunk and branches were significantly improved, a coronal view showing a small number of PEs in the right main pulmonary artery (white arrow), $\mathbf{b}$ axial view showing no significant PEs in the left and right main pulmonary arteries (white arrow)

reconstruction, multiple ligament reconstruction and repair with arthroscopy have been reported [10-12]. However, no early symptomatic PE with successful therapy after knee arthroscopy has been reported to date.

DVT is the most common cause of PE after arthroscopic knee surgery. In fact, it has been reported that $45 \%$ of patients with lower limb DVT may have PE, among which $75 \%$ of patients are asymptomatic and $4 \%$ have fatal outcomes. Without clinical PE screening, many asymptomatic patients or those with mild symptoms will not seek medical attention or will be misdiagnosed. In this case report, the patient showed no obvious abnormalities on the preoperative venous ultrasound of both lower limbs and blood examination, and the operative time was short. Although anticoagulant therapy was not used after the operation, rehabilitation via functional training and the physical prevention of lower limb DVT in both lower limbs were performed in a timely manner. This case occurred in a 50-year-old female with a BMI of $36.3 \mathrm{~kg} / \mathrm{m}^{2}$, a history of hypertension for 8 years, varicose veins in the ipsilateral lower extremities, and a triglyceride (TG) level of $6.12 \mathrm{mmol} / \mathrm{l}$; due to these characteristics, she was at high risk for DVT and should have been preoperatively treated with drugs and physical training. Recently, genetic predisposition and autoimmune antibodies have been shown to play roles in the development of DVT after knee arthroscopy. We screened for causes of spontaneous or acquired thromboembolism during outpatient follow-up [13]. The results for lupus anticoagulant, antiphospholipid syndrome, myeloproliferative disease, and paroxysmal nocturnal haemoglobinuria were negative. Unfortunately, we did not further test the levels of $\mathrm{V}$ Leiden, prothrombin G20210A, protein C, protein S and antithrombin [14, 15 ] because regardless of the outcome, this would not have changed the patient's treatment pathway. If the patient develops venous thromboembolism again in the future, further examinations will be performed. The patient experience symptomatic PE on the second postoperative day, but no obvious DVT was found in either lower limb during vascular ultrasound re-examination. This event does not preclude the possibility of old thrombus detachment in other parts of the body or acute thrombus detachment in the affected limb. Therefore, blood vessel colour ultrasound of the extremities and even pelvic deep vein colour ultrasound should be
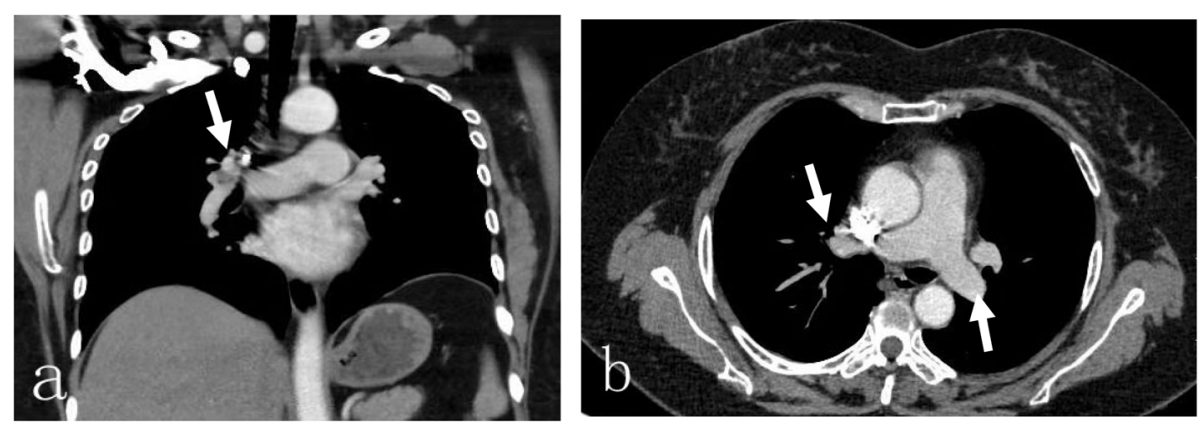

Fig. 3 Pulmonary CTA was performed again on the 6th day after thrombolysis therapy and indicated that the pulmonary thrombi in both lungs were significantly reduced compared to those in the previous examination, with partial revascularization and clear pulmonary vascular lines, a coronal view showing a small number of PEs still in the right main pulmonary artery (white arrow), $\mathbf{b}$ axial view showing no new PEs in the left and right main pulmonary arteries (white arrow) 
routinely performed in patients with abnormal coagulation indicators, a genetic history of thrombosis or a high Caprini risk assessment score during knee arthroscopy to reduce the risk of thrombosis and avoid unnecessary medical disputes. In addition, we hold the opinion that more studies should be conducted to clarify risk factors for VTE development and indications for thromboprophylaxis following knee arthroscopy. Blood stasis, vascular endothelial cell injury, blood hypercoagulability, arthroscopic surgery and the presence of risk factors could lead to the development of DVT. Jiang et al. [16] considered that the use of a tourniquet for a long time could lead to ischaemia reperfusion injury to the tunica intima, thereby resulting in the formation of microthrombi. Dal Molin et al. [17] reported that continuous intraoperative arthrocentesis led to tissue oedema and pressure on peripheral veins, which subsequently led to the occurrence of DVT. Moreover, knee joint endoscopic surgery damages the inner wall of the blood vessels, slows blood flow and leads to the occurrence of DVT due to prolonged inversion, eversion and flexion of the knee joint. The stress response to surgery can activate the patient's endogenous coagulation system, slow blood flow, and lead to the formation of DVT. Surgical trauma can induce the release of tissue factors and cytokines, activate plasminogen activator inhibitor-1, and inhibit the fibrinolytic system, eventually leading to the formation of DVT. Maletis et al. [18] suggested that in elderly patients, DVT formation occurs due to reduced daily activity, decreased muscle and vascular tension and elasticity, and medical conditions such as vascular endothelial injury and increased coagulation factor activity. A recent retrospective case-control study confirmed that patients undergoing arthroscopic knee procedures in centres at high elevations $(>4000 \mathrm{ft}$ ) have a 3.8-times higher risk of developing VTE than those undergoing the same procedures in centres at low elevations [19]. The patient in the current report underwent surgery at an average altitude of $1000 \mathrm{ft}$. in Luzhou, Southwest China.

Early prevention is key in reducing PE after knee arthroscopy or any orthopaedic surgery. The patient's basic medical diseases should be actively treated before surgery, and the patient should be educated early so that they are aware of the existence and risk of thrombosis; the patient should be instructed to perform muscle contraction and diastolic exercises of the lower extremities, including ankle pump exercises and straight leg elevations. The operation should be precise to avoid injury to the blood vessels around the knee joint, and the operation and tourniquet use times should be as short as possible to reduce the risk of ischaemia reperfusion injury. Moreover, the times of knee varus and flexion should be reduced to reduce the risk of injury to the intima caused by vascular distortion. After the operation, it is necessary to closely observe the patient's peripheral blood supply and swelling and pain in the affected limb. Laxative drugs can be given to reduce constipation, and rehabilitation training should be carried out as soon as possible.

\section{Conclusion}

Although knee arthroscopy is minimally invasive and fast, the risk factors for PE in the perioperative period should be considered and fully evaluated to prevent pulmonary embolism. A timely diagnosis and effective treatment are important measures to prevent and cure PE after knee arthroscopy. Finally, clear guidelines regarding VTE thromboprophylaxis following knee arthroscopy in patients with a low risk of VTE development are needed.

\section{Abbreviations \\ PE: Pulmonary embolism; TG: Triglyceride; CTA: Computed tomography angiography; DVT: Deep vein thrombosis; BMI: Body mass index; MRI: Magnetic resonance imaging; ECG: Electrocardiogram; SpO2: Peripheral oxygen saturation; CK-MB: Creatine kinase myocardial band; VTE: Venous thromboembolism}

\section{Acknowledgements}

Not applicable.

\section{Authors' contributions \\ YTD, SCY, ZYS and YNA provided the clinical data included in the text. YL, YXC, PZ and FYD participated in the treatment decisions. $Y L$ and $Y X C$ wrote the manuscript draft. JCL and $Y L$ revised the manuscript critically and approved the modified text. JCL and $\mathrm{ZL}$ approved the final version of the manuscript. All the authors read and approved the final manuscript.}

\section{Funding}

This research is supported by the Cooperation program between Sichuan University and Luzhou municipal people's government (No. 2019cdlz-17). The funders played no role in the collection, analysis and interpretation of data or preparation of the manuscript.

\section{Availability of data and materials}

The datasets used and/or analysed during the current study are available from the corresponding author on reasonable request.

\section{Declarations}

Ethics approval and consent to participate Not applicable.

\section{Consent for publication}

Written informed consent was obtained from the patient for publication of this case report and any accompanying images.

\section{Competing interests \\ The authors declare that they have no competing interests.}

\section{Author details}

'Department of Orthopaedics, the Affiliated Hospital of Southwest Medical University, Sichuan Provincial Laboratory of Orthopaedic Engineering, Luzhou, Sichuan 646000, People's Republic of China. ${ }^{2}$ Department of Intensive Care Unit, the Affiliated Hospital of Southwest Medical University, Luzhou 646000, Sichuan, People's Republic of China. ${ }^{3}$ School of Medicine, Nankai University, Tianjin 300071, People's Republic of China. 
Received: 12 January 2021 Accepted: 15 April 2021

Published online: 24 April 2021

\section{References}

1. Anderson FA Jr, Zayaruzny M, Heit JA, Fidan D, Cohen AT. Estimated annual numbers of US acute-care hospital patients at risk for venous thromboembolism. Am J Hematol. 2007;82(9):777-82. https://doi.org/10.1 002/ajh.20983.

2. Geerts WH, Bergqvist D, Pineo GF, Heit JA, Samama CM, Lassen MR, et al. Prevention of venous thromboembolism: American College of Chest Physicians Evidence-Based Clinical Practice Guidelines (8th edition). Chest. 2008;133(6 Suppl):381S-453S. https://doi.org/10.1378/chest.08-0656.

3. Harris WH, Salzman EW, Desanctis RW. The prevention of thromboembolic disease by prophylactic anticoagulation. A controlled study in elective hip surgery. J Bone Joint Surg Am. 1967:49(1):81-9. https://doi.org/10.2106/ 00004623-196749010-00006.

4. Wirth T, Schneider B, Misselwitz F, Lomb M, Tüylü H, Egbring R, et al. Prevention of venous thromboembolism after knee arthroscopy with lowmolecular weight heparin (Reviparin): results of a randomized controlled trial. Arthroscopy. 2001;17(4):393-9. https://doi.org/10.1053/jars.2001.21247.

5. Abram SGF, Judge A, Beard DJ, Price AJ. Adverse outcomes after arthroscopic partial meniscectomy: a study of 700000 procedures in the national hospital episode statistics database for England. Lancet. 2018; 392(10160):2194-202. https://doi.org/10.1016/S0140-6736(18)31771-9.

6. Lau BC, Jagodzinski J, Pandya NK. Incidence of symptomatic pulmonary embolus and deep vein thrombosis after knee arthroscopy in the pediatric and adolescent population. Clin J Sport Med. 2019;29(4):276-80. https://doi. org/10.1097/JSM.0000000000000519.

7. Flevas DA, Megaloikonomos PD, Dimopoulos L, Mitsiokapa E, Koulouvaris $P$, Mavrogenis AF. Thromboembolism prophylaxis in orthopaedics: an update. EFORT Open Rev. 2018;3(4):136-48.

8. Eynon AM, James S, Leach P. Thromboembolic events after arthroscopic knee surgery. Arthroscopy. 2004;20:23-4. https://doi.org/10.1016/j.arthro.2 004.04.003.

9. Huang HF, Tian JL, Yang XT, Sun L, Hu RY, Yan ZH, et al. Efficacy and safety of low-molecular-weight. heparin after knee arthroscopy: a meta-analysis. PLoS One. 2018;13(6):e0197868.

10. Takigami J, Hashimoto Y, Yamasaki S, Terai S, Nakamura H. A case of asymptomatic bilateral massive pulmonary embolism after arthroscopic multiple knee ligament reconstruction. Knee Surg Sports Traumatol Arthrosc. 2017;25(1):260-2. https://doi.org/10.1007/s00167-014-3466-7.

11. Fang C, Liu H, Zhang J, Yan S. An unusual case of symptomatic deep vein thrombosis and pulmonary embolism after arthroscopic meniscus surgery. Bmc Musculoskel Dis. 2018;19(1):19. https://doi.org/10.1186/s12891-017-191 9-0.

12. Bourget-Murray J, Clarke MA, Gorzitza S, Phillips LA. Symptomatic bilateral pulmonary embolism without deep venous thrombosis in an adolescent following arthroscopic anterior cruciate ligament reconstruction: a case report and review of the literature. J Med Case Rep. 2018;12(1):194. https:// doi.org/10.1186/s13256-018-1726-8.

13. Solari D, Alberio L, Ribi C, Grandoni F, Stalder G. Autoimmune hemolytic Anemia and pulmonary embolism: an association to consider. TH Open. 2021;5(1):e8-e13. https://doi.org/10.1055/s-0040-1721733.

14. Luxembourg B, Henke F, Kirsch-Altena A, Sachs U, Kemkes-Matthes B. Impact of double heterozygosity for factor $V$ Leiden and Prothrombin G20210A on the thrombotic phenotype [published online ahead of print, 2021 Feb 2]. Thromb Res. 2021;200:121-7. https://doi.org/10.1016/j. thromres.2021.01.022.

15. Rapp CM, Shields EJ, Wiater BP, Wiater JM. Venous thromboembolism after shoulder Arthoplasty and arthroscopy. J Am Acad Orthop Surg. 2019;27(8): 265-74. https://doi.org/10.5435/JAAOS-D-17-00763.

16. Jiang $F Z$, Zhong HM, Hong YC, Zhao GF. Use of a tourniquet in total knee arthroplasty: a systematic review and meta-analysis of randomized controlled trials. J Orthop Sci. 2015;20(1):110-23. https://doi.org/10.1007/ s00776-014-0664-6.

17. Polzhofer GK, Petersen W, Hassenpflug J. Thromboembolic complication after arthroscopic shoulder surgery. Arthroscopy. 2003;19(9):e129-32. https:// doi.org/10.1016/j.arthro.2003.09.016.

18. Maletis GB, Inacio MC, Reynolds S, Funahashi TT. Incidence of symptomatic venous thromboembolism after elective knee arthroscopy. JBJS. 2012;94(8): 714-20. https://doi.org/10.2106/JBJS.J.01759.
19. Cancienne JM, Diduch DR, Werner BC. High altitude is an independent risk factor for postoperative symptomatic venous thromboembolism after knee arthroscopy: a matched case-control study of Medicare patients. Arthroscopy. 2017;33(2):422-7. https://doi.org/10.1016/j.arthro.2016.07.031.

\section{Publisher's Note}

Springer Nature remains neutral with regard to jurisdictional claims in published maps and institutional affiliations.

\section{Ready to submit your research? Choose BMC and benefit from:}

- fast, convenient online submission

- thorough peer review by experienced researchers in your field

- rapid publication on acceptance

- support for research data, including large and complex data types

- gold Open Access which fosters wider collaboration and increased citations

- maximum visibility for your research: over $100 \mathrm{M}$ website views per year

At BMC, research is always in progress.

Learn more biomedcentral.com/submissions 